\title{
REVIEW
}

\section{The fate of acute myocarditis between spontaneous improvement and evolution to dilated cardiomyopathy: a review}

\author{
A D’Ambrosio, G Patti, A Manzoli, G Sinagra, A Di Lenarda, F Silvestri, G Di Sciascio
}

The World Health Organization/International Society and Federation of Cardiology (WHO/ ISFC) task force on the definition and classification of cardiomyopathies recently updated and reclassified heart muscle diseases. ${ }^{1}$ Myocarditis was defined as "an inflammatory disease of the myocardium . . . diagnosed by established histological, immunological, and immunohistochemical criteria." Three distinct forms of inflammatory cardiomyopathy (that is, myocarditis associated with cardiac dysfunction) are recognised: idiopathic, autoimmune, and infectious. Various infectious factors may cause myocarditis, but viral agents, especially coxsackie group B viruses, are most commonly associated with this disease. ${ }^{2}$

Myocarditis has been recognised for almost two centuries, since Corvisart first described this disease in clinical terms in $1812,{ }^{3}$ but in the last three decades there has been renewed interest in the inflammatory process in the myocardium. The reasons for this are multiple: the introduction of endomyocardial biopsy for in vivo diagnosis (the disease was often overdiagnosed in the past on purely clinical grounds $)^{4}$; related efforts to produce standardised criteria for histological diagnosis (the Dallas criteria; fig 1$)^{5}$; better understanding of cardiotropic viruses, studied in animal models of myocarditis, ${ }^{6}$ leading to new insights into the immunological mechanisms of the disease (fig $2)^{7}$ and potential treatments in humans ${ }^{8}$; and lastly - and perhaps most interestingly - the finding of a possible causal relation between viral myocarditis and dilated cardiomyopathy, ${ }^{9}$

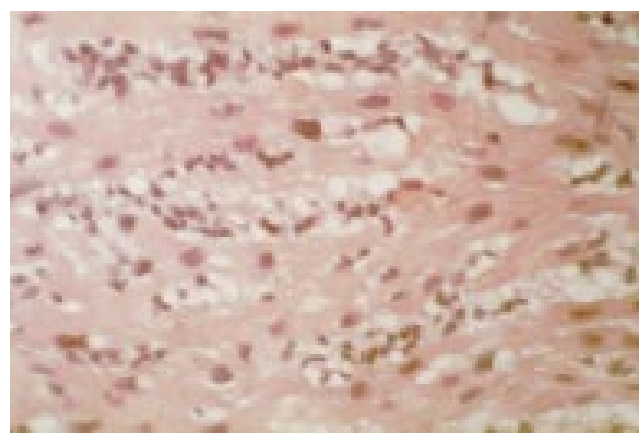

Figure 1 Histological section of active lymphocytic myocarditis according to the Dallas criteria. A dense infiltrate of lymphocytes in close contact with damaged and necrotic myocytes is evident (haematoxylin and eosin $\times 100$ ). a major cause of congestive heart failure in western countries.

Despite numerous published reports on this disease, the natural history of acute myocarditis is still poorly understood, despite the development of immunological and molecular tools for investigating viral diseases which have improved our understanding of their long term course, and in some cases have identified persistence of viruses in the myocardium. ${ }^{10}$

In this review we describe our personal experience on the natural history of biopsy proven acute myocarditis of viral or unknown origin, and we review current reports.

\section{Natural history of acute myocarditis}

The natural history of acute myocarditis is largely unknown. There have been few studies on its short and long term evolution, reflecting the difficulties in diagnosing and following up the disease. Lately, the contribution of endomyocardial biopsy has been invaluable, making early diagnosis of the disease possible, with histological identification of the time course of the inflammatory process.

Nevertheless, several questions remain unsolved. First, as acute myocarditis is rarely symptomatic, it is difficult to identify subclinical episodes ${ }^{11}$ and their possible evolution to disease indistinguishable from idiopathic dilated cardiomyopathy. ${ }^{12}{ }^{13}$ Furthermore, among symptomatic patients, even after the wide acceptance of the standard Dallas pathological criteria, ${ }^{5}$ possible interobserver variability in the interpretation of biopsy specimens,${ }^{14}$ different selection criteria, and the intrinsic limitations of the procedure (number of biopsy

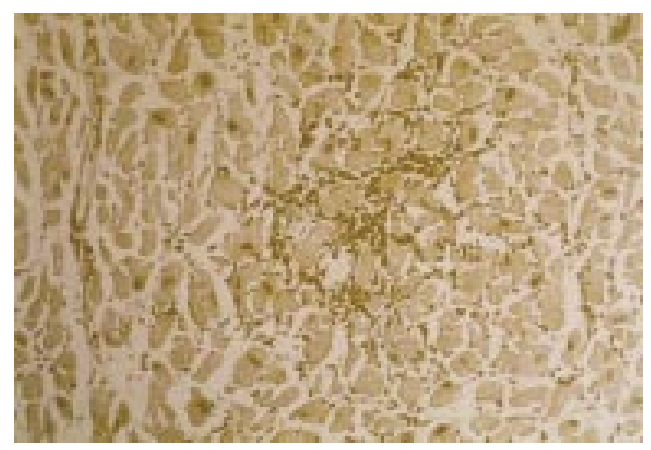

Figure 2 CD4RO positive T lymphocytic cellular infiltrates in a diffuse pattern $(\times 40)$. 


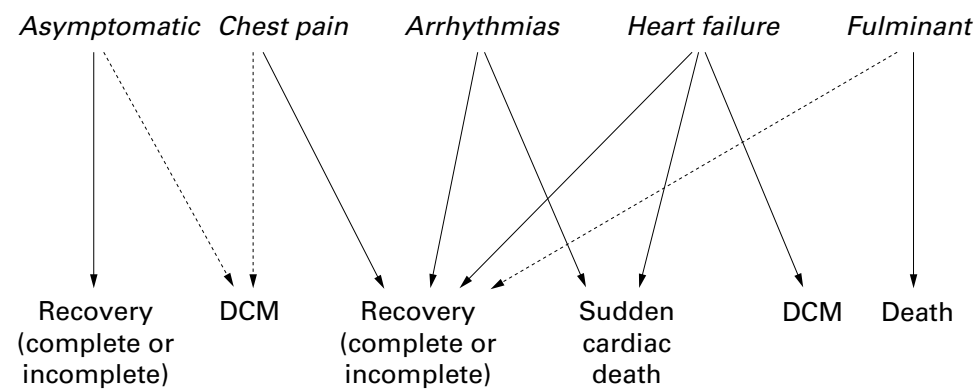

Figure 3 Clinical presentation and evolution of acute viral myocarditis (dotted lines indicate potential evolution). DCM, dilated cardiomyopathy.

specimens, sampling error, reduced sensitivity) ${ }^{14} 15$ have led to high variability in the reported incidence of myocarditis in different series (ranging from 0-67\%). ${ }^{13}{ }^{16}$ Finally, the time interval between symptom presentation and endomyocardial biopsy is crucial: histological signs of inflammation usually recover relatively soon after the onset, so that later morphological diagnosis may be difficult in clinical practice. ${ }^{17}$

In order to predict the natural history of biopsy proven acute myocarditis, we have differentiated patients according to their clinical presentation. ${ }^{18}$ Patients with acute myocardial infarction-like presentation usually have a good prognosis, with a complete or partial recovery of cardiac function, ${ }^{18-20}$ although in a minority cases $(12.5 \%$ in our series) progressive left ventricular dysfunction may occur. Patients with bradyarrhythmias may follow a similar course. Fulminant myocarditis, particularly in paediatric patients, is characterised by dramatically high early mortality (more than $75 \%),{ }^{18}{ }^{21}$ generally from multisystem failure. ${ }^{1822}$ Acute myocarditis with supraventricular arrhythmias at the onset usually follows a

Table 1 Evolution to dilated cardiomyopathy in patients with acute myocarditis

\begin{tabular}{|c|c|c|c|c|}
\hline Reference & $\begin{array}{l}\text { Number of } \\
\text { patients }\end{array}$ & Diagnosis & $\begin{array}{l}\text { Evolution to } \\
\text { DCM (\%) }\end{array}$ & Mean follow up or range \\
\hline Bengtsson $1966^{30}$ & 90 & Clinical & 15 & 60 months \\
\hline Helin $1968^{31}$ & 12 & Clinical & 0 & 7 months \\
\hline Sainani $1968^{32}$ & 19 & Clinical & 0 & 3 months \\
\hline Smith $1970^{33}$ & 42 & Clinical & 7 & 84 months \\
\hline Gerzen $1972^{34}$ & 18 & Clinical & 28 & 12 months \\
\hline Levi $1977^{35}$ & 10 & Clinical & 0 & $42-68$ months \\
\hline Kitaura $1979^{36}$ & 11 & Histology & 27 & $18-156$ months \\
\hline Edwards $1982^{37}$ & 5 & Histology & 20 & $6-12$ months \\
\hline Kayakawa $1983^{38}$ & 20 & Clinical & 30 & 49 months \\
\hline Fenoglio $1983^{21}$ & 18 & Histology & 17 & 12 months \\
\hline Kavakawa $1984^{39}$ & 10 & Clinical & 30 & 55 months \\
\hline Daly $1984^{40}$ & 9 (IS 9) & Histology & 22 & 6 months \\
\hline Dec $1985^{13}$ & 18 & Histology & 11 & $6-12$ months \\
\hline Das $1985^{41}$ & 18 & Clinical & 11 & 54 months \\
\hline Billingham $1986^{42}$ & 20 (IS 15) & Histology & 40 & 5 months \\
\hline Giesecke1987 24 & 45 & Clinical & 11 & 3 months \\
\hline Quigley $1987^{12}$ & 23 & Histology & 52 & 43 months \\
\hline Weiss $1987^{43}$ & 13 (IS 1 ) & Histology & 46 & 36 months \\
\hline Anderson $1987^{44}$ & 10 & Histology & 20 & $6-12$ months \\
\hline Sekiguchi $1988^{17}$ & 20 & Histology & 10 & 49 months \\
\hline Salvi $1990^{45}$ & 38 (IS 28) & Histology & 29 & 49 months \\
\hline Davidoff $1991^{46}$ & 36 (IS 20) & Histology & 19 & 30 months \\
\hline Sekiguchi $1994^{47}$ & 90 & Histology & 14 & 45 months \\
\hline Maisch $1994^{48}$ & 21 & Histology & 28 & 6 months \\
\hline Mason $1995^{27}$ & 47 & Histology & 17 & 52 months \\
\hline Sinagra $1997^{18}$ & 56 (IS 36) & Histology & 39 & 48 months \\
\hline Total & 719 & & Mean $21 \%$ & Mean f/u 33 months \\
\hline
\end{tabular}

Published data on the incidence of progression to dilated cardiomyopathy in patients with clinical or histological diagnosis of acute myocarditis of viral or unknown origin.

DCM, dilated cardiomyopathy; f/u, follow up; IS, number of patients treated with immunosuppressive drugs (no placebo controlled data). favourable course, whereas ventricular arrhythmias may cause cardiopulmonary arrest which is fatal if not promptly diagnosed and treated. ${ }^{23}$ Patients with aborted sudden cardiac death are at risk of recurrent life threatening arrhythmias even after resolution of the inflammatory process, because of the persistence of the arrhythmogenic substrate (that is, reparative fibrosis). ${ }^{23}$ In the large subset of patients presenting with congestive heart failure there is a different potential evolution, ranging from partial or complete recovery to progressive evidence of dilated cardiomyopathy (left ventricular systolic dysfunction, eventually with right ventricular involvement, generally associated with ventricular dilatation) (fig 3). Thus the natural history of acute myocarditis may include either "spontaneous" improvement or deterioration to dilated cardiomyopathy.

\section{Spontaneous improvement}

In past reports, spontaneous improvement has been described in up to $70 \%$ of suspected cases of endemic viral myocarditis diagnosed entirely on clinical grounds. ${ }^{24}$ After the introduction of endomyocardial biopsy, the real incidence remains uncertain. Both Dec and colleagues and Olsen and associates reported spontaneous improvement in $40-50 \%$ of patients with histologically confirmed acute myocarditis. ${ }^{1325}$ More recently, Maisch and colleagues performed a meta-analysis of data currently available in a mixed cohort of patients with or without biopsy (pool of 12 studies, 388 patients followed up for 3-60 months). ${ }^{26}$ This analysis showed variability in spontaneous resolution, with an average of $57 \%$ of patients improving with medical treatment and restriction of physical activity alone. These data are in agreement with those observed in the recent myocarditis treatment trial ${ }^{27}$ performed in patients with a histological diagnosis of acute myocarditis. In our experience of 54 patients with biopsy proven acute myocarditis, the overall incidence of spontaneous improvement was $50 \%$, and improvement was more common among patients with chest pain or arrhythmias at the onset. ${ }^{18}$ Thus spontaneous improvement seems to be relatively frequent in acute myocarditis, which should be borne in mind when deciding whether to start immunosuppressive or antiviral treatment in the acute phase of the disease.

\section{Evolution to dilated cardiomyopathy}

Approximately 36 years ago acute viral myocarditis was suggested as a potential cause of dilated cardiomyopathy. ${ }^{28}$ This hypothesis has been supported by several studies, but definitive proof of the link is still lacking. Studies in animal models show progressive ventricular dysfunction and dilatation in the presence of chronic viral myocarditis. ${ }^{29}$ Long term follow up studies on patients with acute myocarditis have shown a variable incidence of dilated cardiomyopathy, ranging from $0-52 \%$, over a mean period of three years (range three months to 13 years) (table 1). However, studies based on clinical diagnosis alone $e^{24} 30-35383941$ should be differentiated from those based on endomyocardial 
biopsy findings, ${ }^{12} 131718212736374042-48$ as well as from studies investigating patients treated with or without immunosuppressive drugs.

Among the histological studies, the incidence of dilated cardiomyopathy varies from $14 \%$ in the ISFC survey ${ }^{47}$ to $40 \%$ in the study by Billingham and Tazelaar ${ }^{42}$ and $52 \%$ in the series of Quigley and colleagues. ${ }^{12}$ These data, however, reflect differences in diagnosis and patient selection. In particular, Quigley and colleagues described evolution to dilated cardiomyopathy in a group of 23 patients with biopsy proven acute myocarditis during a five year follow up. ${ }^{12}$ In the ISFC survey, ${ }^{47}$ a multicentre and retrospective study performed between 1990 and 1992 on 90 cases of acute viral myocarditis (nine of them postmortem), evolution to dilated cardiomyopathy during a mean 45 months of follow up was observed in $14 \%$. Similar data were reported in previous studies from Japan. ${ }^{49}{ }^{50}$ However, the above mentioned studies predominantly investigated advanced stages of heart failure, characterised by a high early mortality (up to $32 \%$ ). While we observed evolution to dilated cardiomyopathy in $62 \%$ of patients with heart failure symptoms at presentation, the incidence was significantly lower in those with clinical presentation other than congestive heart failure $(5 \%, \mathrm{p}<0.05))^{51}$ According to some investigators, ${ }^{27}{ }^{52}$ endomyocardial biopsy in patients with idiopathic dilated cardiomyopathy may identify a relatively high incidence (4-10\%) of Dallas histological criteria for active myocarditis. On the other hand, the finding of high or rising enterovirus specific antibody titres in some patients with dilated cardiomyopathy is an indication of a previous enteroviral infection. ${ }^{53}$ More recently, the application of molecular technology to the clinical diagnosis of infectious disease has shown genomic viral persistence in myocardial samples in a widely variable percentage of patients with dilated cardiomyopathy (ranging from $0-76 \%) .{ }^{10}{ }^{54-56}$ This variability could be explained by the different molecular biological techniques used (increasing sensitivity and specificity with nested polymerase chain reaction compared with slotblot hybridisation), the different number of biopsy samples (influencing the probability of sampling error), and different types of sample processing (better sensitivity and reproducibility with frozen samples than with fixed ones). In addition, there is potential for contamination in the processing of samples with enteroviral pathogens, especially if tissue is collected by the cardiologist and processed through the pathology laboratory. This possibility needs to be taken into account.

\section{Long term prognosis}

The long term prognosis of acute myocarditis of suspected viral origin was usually good in initial reports of small groups of patients diagnosed on clinical grounds alone. ${ }^{57} 58$ This observation has subsequently been confirmed by Dec and colleagues in a series of 18 patients with biopsy proven lymphocytic myocarditis followed up for three years (15 survived $(83 \%)) .{ }^{59}$ More recently, however, Grogan and associates found no difference in survival between patients with biopsy proven acute myocarditis (56\%) and idiopathic dilated cardiomyopathy with negative biopsy findings (54\%) during a five year follow up of 27 patients. ${ }^{60}$ We found a similar four year transplant-free survival (54\%) in a group of patients with acute myocarditis and heart failure symptoms, compared with $87 \%$ in patients with other types of clinical presentation (arrhythmias and chest pain) $(\mathrm{p}<0.05) .{ }^{51}$ In agreement with Grogan and associates, we observed increased morbidity and long term mortality in the subset of patients with congestive heart failure at presentation.

\section{Factors in prognosis}

Definitive data on predictors of long term prognosis in patients with acute myocarditis are lacking. As we have already suggested, knowledge of the type of clinical presentation may be helpful in establishing an early and often correct clinical prognosis. In a preliminary analysis we observed that patients with chest pain or advanced atrioventricular block at onset had a good prognosis on long term follow up and none developed dilated cardiomyopathy. ${ }^{45}$ There was a strong suggestion that the shorter clinical history and the better left ventricular function at onset in this subset of patients might explain their favourable course in comparison with patients who already had congestive heart failure at presentation. More recently, ${ }^{51}$ in a series of 60 patients (34 male, 26 female; mean (SD) age, 35 (15) years) with biopsy proven acute myocarditis followed up for 48 (46) months, we observed a reduced four year transplant-free survival in those with congestive heart failure $(p<0.05)$ (fig 4); moreover, left ventricular end diastolic diameter at diagnosis and lack of improvement on short term follow up (9 (3) months) predicted long term evolution to dilated cardiomyopathy $(p<0.05)$ and death or heart transplantation $(p<0.05)$ in patients with heart failure at presentation. Goldberg and colleagues, in a similar series of 109 patients with acute histologically diagnosed myocarditis (median follow up 98

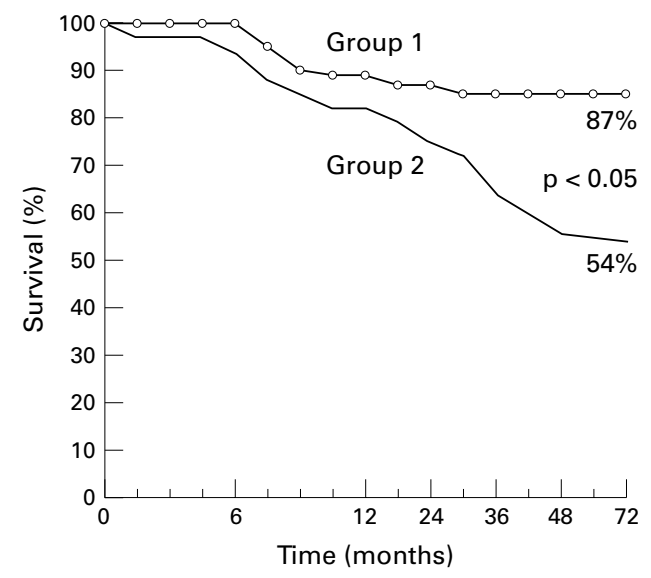

Figure 4 Four year transplant-free survival curves in patients with arrhythmic or acute myocardial infarction-like presentation (group 1) v patients with heart failure presentation (group 2). Mean (SD) follow up, 48 (46) months. Modified from Sinagra et al. G Ital Cardiol 1997;27:758-74. 
months), confirmed the predictive value of ventricular function and ECG abnormalities (presence of bundle branch block), and emphasised that syncope was a particularly unfavourable presenting symptom. ${ }^{61}$ Recently, McCarthy and colleagues, in a 13 year experience at the Johns Hopkins Hospital, observed that patients with fulminant myocarditis who survive from the acute phase with aggressive haemodynamic support are most likely to have a complete recovery of left ventricular function, with an excellent long term prognosis, compared with patients with acute non-fulminant myocarditis $(\mathrm{p}=0.05) .{ }^{62}$

Among other variables, reduced left ventricular ejection fraction at onset is clearly the main predictor of decreased survival in patients with acute myocarditis. ${ }^{59}$ Quigley and colleagues identified the positive prognostic value of preserved left ventricular systolic function or of its early normalisation (within 6-8 months) in the natural history of myocarditis. ${ }^{12}$ As only a subgroup of patients with acute myocarditis appears to develop dilated cardiomyopathy, the prognostic value of left ventricular dysfunction may depend on the exact time when it is observed in the natural history of the disease. However, Weiss and associates emphasised that the clinical status during follow up (based on radionuclide assessment of left ventricular function), even after 12-15 months from onset, did not necessarily predict long term outcome owing to the potential recurrence of autoimmune inflammatory process. ${ }^{43}$

ECG abnormalities such as QRS alterations, atrial fibrillation, or low voltages may predict an unfavourable clinical course of acute myocarditis, reflecting more extensive myocardial injury. ${ }^{63}$ Positive serology for coxsackievirus $\mathrm{B}$ was also an unfavourable predictive factor for acute myocarditis in a 15 year follow up study ${ }^{57}$ although this observation was not confirmed in a successive series of patients with coxsackievirus myopericarditis observed for 23 years. ${ }^{58}$ This apparent discordance may be explained by the low incidence of congestive heart failure at onset in the latter group of patients. Histological findings in endomyocardial biopsy samples obtained in the acute phase of myocarditis have been evaluated as a predictive marker of subsequent haemodynamic and clinical status. The conclusions are conflicting at present. Quigley and colleagues did not identify any histological pattern that could predict the long term outcome, ${ }^{12}$ contrary to a previous report from the same group. ${ }^{64}$ More recently, Sakai and associates observed that Azan Mallory staining of myocytes may be useful in predicting haemodynamic improvement in patients with acute myocarditis. ${ }^{65}$

\section{Molecular biological predictors}

The recent development and wide application of molecular biological techniques for the detection of viral genome in the myocardium (slot-blot hybridisation, in situ hybridisation, and polymerase chain reaction) have made a fresh contribution to our understanding of the natural history of myocarditis. Bowles and colleagues have identified enteroviral genome by slot-blot hybridisation from biopsy samples of patients with acute myocarditis, ${ }^{10}$ dilated cardiomyopathy, ${ }^{10}$ and end stage dilated cardiomyopathy (explanted hearts), ${ }^{66}$ concluding that persistence of virus after enteroviral myocarditis might predispose to the later development of dilated cardiomyopathy, and that virus might persist in the myocardium until the end stage of the disease. ${ }^{66} \mathrm{~A}$ study by Archard and associates confirmed the importance of viral persistence: they observed that enteroviral persistence in the myocardium (coxsackievirus B) was the strongest predictive factor of mortality in patients with dilated cardiomyopathy or acute myocarditis $(p=0.02$; length of follow up 24 months). ${ }^{67}$ Subsequently, Why and colleagues prospectively evaluated 120 patients with heart muscle disease (43 with histological diagnosis of myocarditis, 77 with dilated cardiomyopathy), dividing them into two groups on the basis of the presence or absence of enteroviral RNA sequences in the first endomyocardial biopsy specimens (slot-blot hybridisation). ${ }^{68}$ Mortality and progression to cardiac transplantation during the follow up (mean length 25 months) was greater in the enterovirus positive group than in the enterovirus negative group ( $25 \% v 4 \%, p=0.02)$; the detection of enterovirus RNA in the myocardium has been shown by multivariate regression analysis to be an independent predictor of clinical outcome. More recently, Figulla and colleagues found that enterovirus positive patients (in situ hybridisation) with left ventricular dysfunction had a better prognosis than enterovirus negative patients, ${ }^{69}$ and speculated that myocardial enterovirus infection with associated left ventricular dysfunction is a distinct disease entity with a benign course. At present, the precise correlation between persistence of viral infection and prognosis has still to be determined. Preliminary reports show that enterovirus may persist in a defective form, ${ }^{66} 70$ thus causing a lack of inflammatory response in the myocardium and at the same time modulating cardiac gene expression (a process already observed in the failing heart). ${ }^{71}$ Moreover, virus persistence may provoke an immune mediated process with further deterioration of cardiac function.

\section{Conclusions}

Acute myocarditis may be asymptomatic and present with a benign subclinical course. The natural history of symptomatic myocarditis varies from early death from multisystem failure (fulminant myocarditis) or ventricular arrhythmias, to complete recovery or long term evolution to dilated cardiomyopathy. The type of clinical presentation plays an important role in the prognosis - cardiac death and the need for heart transplantation is significantly more likely in patients with heart failure symptoms at onset. ${ }^{18}$ Some non-invasive variables evaluated at clinical presentation show good predictive accuracy in this subset of patients with acute myocarditis. These include left ventricular systolic function and end diastolic diameter, ECG alterations, and the improvement occurring during short term follow up.

In our opinion, these clinical and noninvasive variables may help cardiologists to 
identify early those patients with acute myocarditis of viral or unknown origin who need more aggressive treatment. Such patients need close follow up to evaluate the timing of possible heart transplantation.

1 Richardson P, McKenna W, Bristow M, et al. Report of the 1995 World Health Organisation/International Society and Federation of Cardiology task force on the definition and classification of cardiomyopathies. Circulation 1996;93:341-2

2 Martino TA, Liu P, Petric M, et al. Enteroviral myocarditis and dilated cardiomyopathy: a review of clinical and experimental studies. In: Rotbart HA, ed. Human enterovirus infections. Washington DC: American Society for rus infections. Washington DC
Microbiology, 1995:291-351.

3 Corvisart JN. Essai sur les maladies et les lésions organisque du coeur. Gates 7 MMSS 1812;182:299-303.

4 Sakakibara S, Konno S. Endomyocardial biopsy. fpn Heart $\mathcal{f}$ 1962:3:537-43.

5 Aretz HT, Billingham ME, Edwards WD, et al. Myocarditis: a histopathological definition and classification. $\mathrm{Am} \mathcal{F} \mathrm{Car}$ diovasc Pathol 1987;1:3-14.

6 Matsumori A. Animal models: pathological findings and therapeutic considerations. In: Banatvala JE, ed. Viral infections of the heart. London: Edward Arnold, 1993:110-37.

7 Craighead JE, Huber SA, Sriham S. Biology of disease. Animal models of picornavirus-induced autoimmune disease: their possible relevance to human disease. Lab Invest 1990 ; 63:432-46.

8 Maisch M, Herzum M, Hufnagel G, et al. Immunosuppressive and immunomodulatory treatment for myocarditis. sive and immunomodulatory trea

9 Sole MJ, Liu P. Viral myocarditis: a paradigm for understanding the pathogenesis and treatment of dilated cardiomyopathy. 7 Am Coll Cardiol 1993;22(suppl A):99105.

10 Bowles NE, Richardson PJ, Olsen EGJ, et al. Detection of coxsackie-B-virus-specific RNA sequences in myocardial biopsy samples from patients with myocarditis and dilated cardiomyopathy. Lancet 1986;i:1120-3.

11 Peters NS, Poole-Wilson PA. Myocarditis-continuing clinical and pathologic confusion. Am Heart $\mathcal{F}$ 1991;121: 942-7.

12 Quigley PJ, Richardson PJ, Meany BT, et al. Long-term follow up of acute myocarditis. Correlation of ventricular function and outcome. Eur Heart f 1987;8 (suppl I):39-42.

13 Dec GW, Palacios IF, Fallon JT, et al. Active myocarditis in the spectrum of acute dilated cardiomyopathies. N Engl F the spectrum of acute $1985 ; 312: 885-90$.

14 Shanes JG, Ghali J, Billingham ME, et al. Interobserver variability in the pathologic interpretation of endomyocardial biopsy results. Circulation 1987;75:401-5.

15 Hauck AJ, Kearney DL, Edwards WD. Evaluation of postmortem endomyocardial biopsy specimens from 38 patients with lymphocytic myocarditis: implications for role of sampling error. Mayo Clin Proc 1989;64:1235-45.

16 Rose AG, Fraser RC, Beck W. Absence of evidence of myocarditis in endomyocardial biopsy specimen from patients with dilated (congestive) cardiomyopathy. S Afr Med $f$ 1984;66:871-4.

17 Sekiguchi M, Hiroe M, Hiramitsu S, et al. Natural history of acute viral or idiopathic myocarditis: a clinical and endomyocardial biopsy follow-up. In: Schulteiss HP, ed. New concepts in viral heart disease. Berlin: Springer Verlag, 1988:33-50.

18 Sinagra G, Maras P, D'Ambrosio A, et al. Polimorfismo clinico di presentazione e storia naturale della miocardite attiva: esperienza su 60 casi. G Ital Cardiol 1997;27:75874.

19 Costanzo-Nordin MR, O'Connell JB, Subramanian R, et al. Myocarditis confirmed by biopsy presenting as acute myocardial infarction. Br Heart $\mathcal{F}$ 1985; 53:25-9.

20 Dec GW, Waldman H, Southern J, et al. Viral myocarditis mimicking acute myocardial infarction. f Am Coll Cardiol 1992;20:85-9.

21 Fenoglio JJ, Ursell PC, Kellogg CF, et al. Diagnosis and classification of myocarditis by endomyocardial biopsy. $N$ Engl F Med 1983;308:12-18.

22 Stiller B, Dahnert I, Weng YG, et al. Children may survive myocarditis with prolonged use of biventricular assist myocarditis with prolonged use
devices. Heart 1999;82:237-40.

23 Vignola PA, Aonuma K, Swaye PS, et al. Lymphocytic myocarditis presenting as unexplained ventricular arrhythmias:
diagnosis with endomyocardial biopsy and response to diagnosis with endomyocardial biopsy and response

24 Giesecke J. The long-term prognosis in acute myocarditis. Eur Heart $\mathcal{F} 1987 ; 8$ (suppl J):251-3.

25 Olsen EGJ, Meany BT, Richardson PJ. The role of biopsy in the diagnosis and follow up of myocarditis: a critical review. In: Schultheiss, ed: New concepts in viral heart disease. Berlin: Springer Verlag, 1988:285-94.

26 Maisch B, Herzum M, Hufnagel G, et al. Immunosuppressive treatment for myocarditis and dilated cardiomyopathy. Eur Heart F 1995;16(suppl O):153-61.

27 Mason JW, O'Connell JB, Herskowitz A, et al. A clinical trial of immunosuppressive therapy for myocarditis. $N$ Engl $\mathcal{F}$ Med 1995;333:269-75.

28 Burch GE, De Pasquale NP. Viral myocarditis. In: Churchill JA, ed: Cardiomyopathies. London: Churchill, 1964:99-115.
29 Matsumori A, Kawai C. An animal model of congestive (dilated) cardiomyopathy: dilation and hypertrophy of the heart in chronic stage in DBA/2 mice with myocarditis caused by encephalomyocarditis virus. Circulation 1982;66: 355-60.

30 Bengtsson E, Lamberger B. Five-year follow up study of cases suggestive of acute myocarditis. Am Heart f 1966;72: $751-63$.

31 Helin M, Savola J, Lapinleimu K. Cardiac manifestations during a coxsackie B5 epidemic. BMF 1986;3:97-9.

32 Sainani GS, Krompotic E, Slodki SJ. Adult heart disease due to coxsackie virus B infection. Medicine 1968;47:133-47.

33 Smith WG. Coxsackie B myopericarditis in adults. Am Heart f 1970;80:34-46.

34 Gerzen P, Granath A, Holmgran B, et al Acute myocarditis: a follow up study. Br Heart $\mathcal{F} 1972 ; 34: 575-83$.

35 Levi GF, Proto C, Quadri A, et al. Coxsackie virus heart disease and cardiomyopathy. Am Heart $\mathcal{F}$ 1977;93:419-21.

36 Kitaura Y, Morita H. Secondary myocardial disease. Viru myocarditis and cardiomyopathy. Fpn Circ $\mathcal{F}$ 1979;43:101731 .

37 Edwards WD, Holmes DR, Reeder GS. Diagnosis of active lymphocytic myocarditis by endomyocardial biopsy. Quantitative criteria for light microscopy. Mayo Clin Proc 1982;57:419-25.

38 Kayakawa M, Inoh T, Yokota $\mathrm{Y}$, et al. A long term follow-up study of acute viral and idiopathic myocarditis. Fpn Circ $\mathcal{F}$ 1983;47:1304-9.

39 Kayakawa $M$, Inoh T, Yokota Y, et al. A long-term follow-up study of acute myocarditis: an electrocardiographic and echocardiographic study. Fpn Circ F 1984;48:1362-7.

40 Daly K, Richardson PJ, Olsen EG, et al. Acute myocarditis. Role of histological and virological examination in the diagnosis and assessment of immunosuppressive treatment. Br Heart f 1984;51:30-5.

41 Das SK, Colfer HT, Pitt B. Long-term follow-up of patients with previous myocarditis using radionuclide ventriculography. Heart Vessels Suppl 1985;1:195-8.

42 Billingham ME, Tazelaar HD. The morphological progression of viral myocarditis. Postgrad Med $\mathcal{f} 1986 ; 62: 581-4$

43 Weiss MB, Marboe CC, Escala EL, et al. Natural history of untreated chronic myocarditis (active myocarditis with fibrosis). Eur Heart $\mathcal{F}$ 1987;8(suppl J):247-50.

44 Anderson JL, Fowles RE, Unverferth DV, et al. Immunosuppressive therapy of myocardial inflammatory disease-
initial experience and further trials to define indications for therapy. Eur Heart f 1987;8(suppl J):263-6.

45 Salvi A, Dreas L, Di Lenarda A, et al. Clinical presentation and evolution in treated and untreated myocarditis. In: Baroldi G, Camerini F, Goodwin JF, eds. Advances in cardiomyopathies. Berlin: Springer Verlag, 1990:316-24.

46 Davidoff R, Palacios I, Southern J, et al. Giant cell versus lymphocytic myocarditis: a comparison of their clinical fealymphocytic myocarditis: a comparison of their clinical fea-

47 Sekiguchi M, Nunoda S, Hiroe M, et al. Prognosis of patients with acute viral myocarditis in whom endomyocardial biopsies and/or autopsies were performed: an ISFC survey. In: Sekiguki M, Richardson PJ, eds. Prognosis and treatment of cardiomyopathies and myocarditis. Tokyo: University of Tokyo Press, 1994:189-200.

48 Maisch B, Schönian U, Hengstenberg C, et al. Immunosuppressive treatment in autoreactive myocarditis-results from a controlled trial. Postgrad Med f 1994;70(suppl 1):S29-34.

49 Take M, Sekiguchi M, Hiroe M, et al. Long term follow-up of electrocardiographic findings in patients with acute myocarditis proven by endomyocardial biopsy. Fpn Circ $\mathcal{F}$ $1982 ; 46: 1227-34$

50 Kawamura K, Kitaura Y, Morita H, et al. Viral and idiopathic myocarditis in Japan: a questionnaire survey. Heart Vessels 1985;1(suppl 1):18-22.

51 Sinagra G, D'Ambrosio A, Bussani R, et al. Clinical presentation and predictive factors of long term outcome in patients with biopsy-proven myocarditis [abstract]. Circulation 1999;33 (suppl A):506A.

52 Herskowitz A, Campbell S, Deckers J, et al. Demographic features and prevalence of idiopathic myocarditis in patients undergoing endomyocardial biopsy. Am 7 Cardiol 1993;84(suppl 2):2-13.

53 Cambridge G, MacArthur CGC, Waterson AP, et al. Antibodies to coxsackie B viruses in congestive cardiomyopathy. Br Heart 7 1979;41:692-6.

54 Weiss L, Mohaved L, Billingham ME, et al. Detection of coxsackie B3 RNA in myocardial tissues by polymerase chain reaction. Am ₹ Pathol 1991;138:497-503.

55 Keeling PJ, Jeffery S, Caforio AL, et al. Similar prevalence of enteroviral genome within the myocardium from patients with idiopathic dilated cardiomyopathy and controls by polymerase chain reaction. Br Heart f 1992;68:554-9.

56 Giacca M, Severini GM, Mestroni L, et al. Low frequency of detection by nested polymerase chain reaction of enterovirus ribonucleic acid in endomyocardial tissue of patients with idiopathic dilated cardiomyopathy. $\mathcal{f} \mathrm{Am}$ Coll Cardiol 1994;24:1033-40.

57 Levi G, Scalvini S, Volterrani M, et al. Coxsackie virus heart diseases: 15 years after. Eur Heart f 1988;9:1303-7.

58 Remes J, Helin M, Vaino P, et al. Clinical outcome and left ventricular function 23 years after acute coxsackie virus myopericarditis. Eur Heart f 1990;11:182-8.

59 Dec GW, Fallon JT, Southern JF, et al. Relation between histological findings on early repeat right ventricular biopsy and ventricular function in patients with myocarditis. $\mathrm{Br}$ Heart f 1988;60:332-7. 
60 Grogan M, Redfield MM, Bailey KR, et al. Long-term outcome of patients with biopsy-proved myocarditis: comparison with idiopathic dilated cardiomyopathy. $f$ Am Coll Cardiol 1995;26:80-4.

61 Goldberg LR, Suk HJ, Patton KK, et al. Predictors of adverse outcome in biopsy-proven myocarditis [abstract]. Circulation 1999;33(suppl A):505A

62 McCarthy RE, Boehmer JP, Hruban RH, et al. Long-term outcome of fulminant myocarditis as compared with acute (nonfulminant) myocarditis. N Engl F Med 2000;342:690-5.

63 Morgera T, Di Lenarda A, Dreas L, et al. Electrocardiography of myocarditis revisited: clinical and prognostic significance of electrocardiographic changes. Am Heart $\mathcal{f}$ 1992;124:455-67.

64 Richardson PJ, Daly K, Gishen P. Haemodynamic findings in biopsy proven acute myocarditis. In: Bolte HD, ed. Viral heart disease. Berlin: Springer Verlag, 1984;165-72.

65 Sakai A, Fukunami M, Nagareda T, et al. Presence of poorly stained myocytes in acute myocarditis predicts improvestained myocytes in acute myocarditis predicts impro

66 Bowles NE, Rose ML, Taylor P, et al. End-stage dilated cardiomyopathy persistence of enterovirus RNA in myocardium at cardiac transplantation and lack of immune response. Circulation 1989;80:1128-36.
67 Archard LC, Bowles NE, Cunningham L, et al. Enterovirus RNA sequences in hearts with dilated cardiomyopathy: a pathogenic link between virus infection and dilated cardiomyopathy. In: Baroldi G, Camerini F, Goodwin JF, eds. Advances in cardiomyopathies. Berlin: Springer Verlag, 1990: 194-8.

68 Why HJF, Meany BT, Richardson PJ, et al. Clinical and prognostic relevance of detection of enteroviral RNA in the myocardium of patients with myocarditis or dilated cardiomyocardium of patients with myocarditis
myopathy. Circulation 1994;89:2582-9.

69 Figulla HR, Stille-Siegener M, Mall G, et al. Myocardial enterovirus infection with left ventricular dysfunction: a benign disease compared with idiopathic dilated cardiomyopathy. 7 Am Coll Cardiol 1995;25:1170-5.

70 Cunningham L, Bowles NE, Lane RJM, et al. Persistence of enterovirus RNA in chronic fatigue syndrome is associated with the abnormal production of equal amounts of positive and negative strands of enteroviral RNA. F Gen Virol 1990; 71:1399-402.

71 Feldman AM, Ray PE, Silan CM, et al. Selective gene expression in the failing human heart. Circulation 1991;83: 1866-72.

\section{IMAGES IN CARDIOLOGY}

\section{Double orifice mitral valve associated with non-compaction of left ventricle}

A 45 year old man was admitted because of dyspnoea on effort and palpitations. He had no familial history of heart disease. An ECG showed left ventricular hypertrophy. Radiographs of the chest revealed mild cardiomegaly. Short axis transthoracic echocardiography
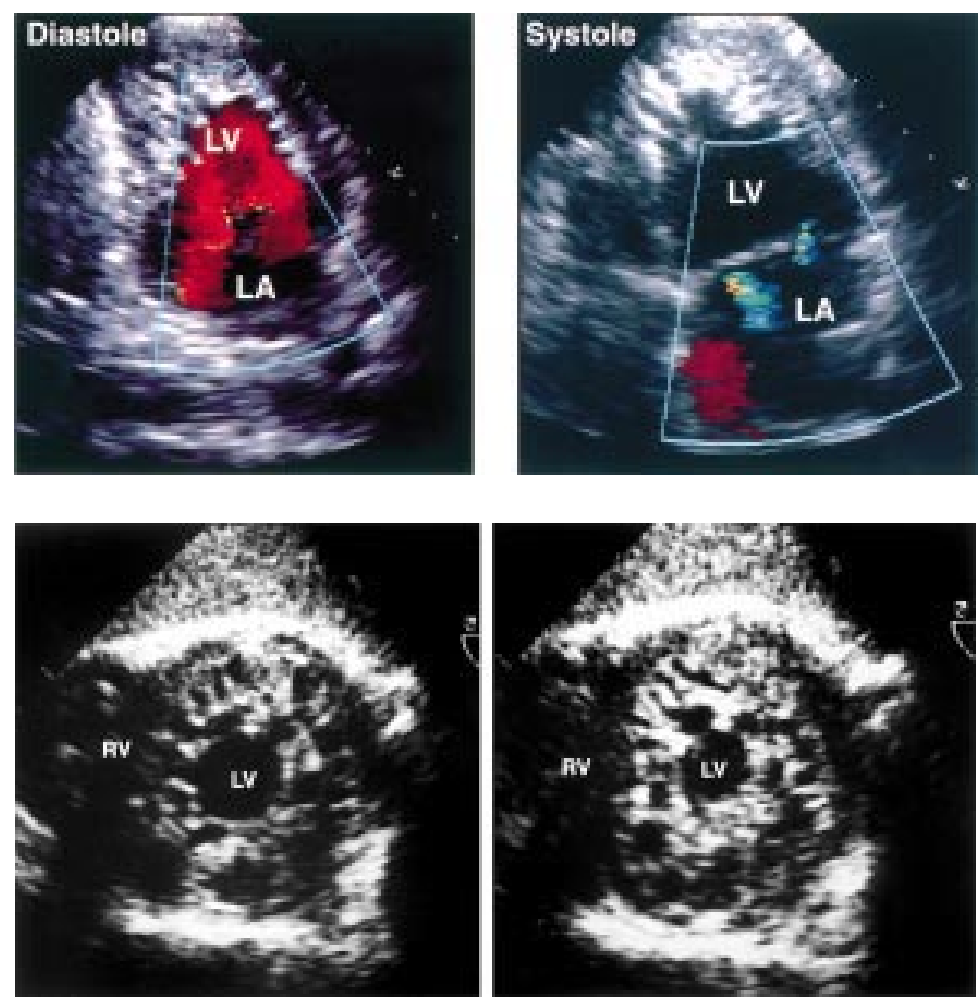

End diastole

End systole indicated the existence of two orifices in the mitral valve. With the apical four chamber view, double left ventricular inflow jets were obtained by colour Doppler at the diastolic phase. Colour Doppler echocardiography also showed mild mitral regurgitation from both orifices. To define double orifice mitral valve and evaluate the subvalvar apparatus in detail, a transoesophageal echocardiograph was performed. Double orifices were clearly visible from the ring of the valve, and each orifice had its own subvalvar apparatus separately at the free part of each leaflet.

An abnormality of the left ventricle was also detected. The left ventricle was dilated and diffusely hypokinetic (end diastolic/end systolic dimension $58 / 48 \mathrm{~mm}$, ejection fraction $30 \%$ ). The left ventricular wall was thickened, especially at the apex, and appeared sponge-like. There were numerous, excessively prominent trabeculations associated with deep intertrabecular recesses. The contrast entered into the intertrabecular recesses. We diagnosed non-compaction of left ventricular myocardium. Treatment with an angiotensin converting enzyme inhibitor and diuretics proved effective. After the patient's symptoms disappeared, $\beta$ blocker treatment with metoprolol was initiated; six months later, the patient's left ventricular dimension was reduced and left ventricular wall motion was improved (end diastolic/end systolic dimension $53 / 32 \mathrm{~mm}$, ejection fraction $52 \%$ ). 